Open Access

\title{
Developing a competency taxonomy for teacher design knowledge in technology- enhanced learning environments: a literature review
}

\author{
Mi Song Kim
}

Correspondence: misong.kim@ gmail.com

Curriculum Studies, University of Western Ontario, London, ON, Canada

\begin{abstract}
Recent research in technology-enhanced learning environments has indicated the need to redefine the role of teachers as designers. This supports successful learners better able to adapt to twenty-first century education, in particular STEM education. However, such a repositioning of teaching as a design science challenges teachers to reconceptualize educational practice as an act of design, not in the artistic meaning of the word. Our recent research finding also indicated that teacher design knowledge (TDK) processes are often invisible to both the teacher educators and the teachers. To respond to these challenges, this paper will define TDK for STEM teachers by making TDK visible in the form of a TDK competency taxonomy. A systematic literature review was conducted to identify the characteristics of teaching practices in technology-enhanced learning environments. This TDK competency taxonomy consists of four main categories drawing on existing literature on teacher design work and teacher instructional design: data practice, design practice, knowledge creation practice, and professional teaching practice. The implications of these findings were discussed.
\end{abstract}

Keywords: Teacher design knowledge (TDK), TDK competency taxonomy, STEM teachers, Teachers-as-designers, Technology-enhanced learning environments

\section{Springer Open}

\section{Highlights}

- Recent research in technology-enhanced learning environments has indicated the need to redefine the role of teachers as designers.

- Teacher design knowledge (TDK) processes are often invisible to both the teacher educators and the teachers.

- This paper defines TDK competencies for STEM teachers by making TDK visible in the form of TDK competency taxonomies.

- These TDK competency taxonomies consist of four main categories: data practice, design practice, knowledge creation practice, and professional teaching practice.

(c) The Author(s). 2019 Open Access This article is distributed under the terms of the Creative Commons Attribution 4.0 International License (http://creativecommons.org/licenses/by/4.0/), which permits unrestricted use, distribution, and reproduction in any medium, provided you give appropriate credit to the original author(s) and the source, provide a link to the Creative Commons license, and indicate if changes were made. 


\section{Introduction}

How can we empower teachers to become more engaged in designing innovative technology-enhanced learning activities for deep student learning? There is a growing consensus that greater teacher engagement in design tasks leads to greater student achievements in Science, Technology, Engineering, and Mathematics (STEM). Recent advances in technology-enhanced learning environments also emphasize "the critical importance of teachers as designers" of technology enhanced learning (McKenney, Kali, Markauskaite, \& Voogt, 2015, p. 182). However, little attention has been paid to developing teacher education programs to support teacher design learning. Our recent systematic review of the design work of STEM teachers (Kim, 2019) indicates that much of the difficulty stems from the fact that the term of teacher design knowledge (TDK) has not yet been clearly defined. Further, TDK processes are often invisible to both the teacher educators and the teachers. The review also shows that there is also active debate and discussion around key questions such as: How is teacher design knowledge (TDK) defined? How does TDK relate to STEM education? Who are designers in STEM teaching? To respond to these questions, this paper aims to develop the taxonomy of TDK competencies drawing upon current educational efforts in line with the increasingly design nature of STEM teaching and learning.

\section{The role of teachers in technology-enhanced learning}

Recent research in technology-enhanced learning has indicated the need to redefine the role of teachers as designers (McKenney et al., 2015) to support twenty-first century learning. Such a repositioning of teaching as a creative practice challenges teachers to reconceptualize educational practice as an act of design, not in the artistic meaning of the word, but in the sense of as a collaborative, problem solving activity that results in the creation of something useful that did not exist before (Ertmer, Parisio, \& Wardak, 2013). In traditional education systems, curriculum and assessment were predetermined, the textbooks followed curriculum and assessment, teachers followed the textbooks, and students followed the textbooks through memorizing facts. By contrast, students in the twenty-first century need to be more collaborative, creative, and openmined, as knowledge is increasingly created collaboratively through ubiquitous access to information technology.

It is also important for students to master a diverse set of skills and cultural competencies, so-called multiliteracies (Cope \& Kalantzis, 2000), necessary to navigate the various forms of digital communication and participation in a global society. Multiliteracies is an expanded form of literacy defined as cultural and new media competencies within a multiplicity of modes and mediums (The New London Group, 1996). However, very few teachers have the competencies or the confidence in their abilities to become designers for multiliteracies teaching and learning (Rowsell, Kosnik, \& Beck, 2008).

Although multiliteracies scholars do not explicitly mention design knowledge, multiliteracies pedagogy could inform teacher design knowledge in several ways. First is the belief in the "Learning-by-Design" theory (The New London Group, 1996, 2000) addressing the need to engage teachers in their pedagogical experiments for responding to growing cultural and linguistic diversity in the globalized world and new communication technologies. Multiliteracies' view of meaning-making as a form of design has 
three aspects in the recognition of collective design in the representational process: (1) every meaning draws on resources of the already designed world of representation (available designs); (2) each meaning maker designs the world afresh in a way which is always uniquely transformative of found meanings (the designing); and then (3) leaves a representational trace to be found by others and transformed once again (the Redesigned) (Cope \& Kalantzis, 2000).

Secondly, multiliteracies recognizes a salient role of new technologies to create and manipulate concrete objects in multimodal ways (Jewitt, 2014; Kress, 2000, 2003) of thinking and learning about abstract concept formation. As such, teachers need to understand new ways to engage with technology to support students' multiliteracies capacities: proficiency in meaning-making in linguistic, visual, audio, gestural, spatial, and multimodal designs. Teachers must now support new kinds of learners who are able to navigate change and diversity, solve complex problems, collaborate, and be flexible and creative.

Advocacy for this change is grounded in a new paradigm of learning through which knowledge is co-constructed through social interactions with the broader social group (Sfard, 1998). Thus, thirdly, multiliteracies gives teachers novel insights into pedagogy by extending their pedagogical repertoires to facilitate both collective and personal knowledge construction because of new digital technologies and the globalizing knowledge economy (McKenney et al., 2015). To be productive participants in these social learning approaches requires not only traditional literacy skills (e.g., reading, writing) but what Kalantzis, Cope, and Harvey (2003) describes as the "new basics" referring to actively communicating in an unfamiliar context and learning from successes and mistakes (p. 23). New learning certainly calls for new perspectives on teaching.

These changes reflect a new understanding of how, where, and when people are learning (Kim, Hung, Jamaludin \& Lim, 2012). Due to the rapid emergence of digital technologies, it is also clear that knowledge, more aptly phrased "knowing about," is no longer viewed as a static entity residing in the individual's head. Rather, education needs to focus more on supporting learners in engaging in the collaborative construction of various digital artifacts and facilitating authentic practice that mirrors expert practitioners in a field-that is "a participatory learning environment" (Barab, Hay, Barnett, \& Squire, 2001). Thus, learning in the twenty-first century is viewed as a process of participating in authentic contexts by gradually becoming expert-like full participants and by jointly designing various multimodal semiotic tools and artifacts. However, this learning often is relegated to informal learning contexts like "after-school programs rather than being integrated across curricula" (Reilly, 2011, p. 6) in formal (school) learning settings.

\section{Methods}

This paper will define teacher design knowledge (TDK) for STEM teachers by making TDK visible in the form of a competency taxonomy for TDK. A systematic literature review was conducted to identify the characteristics of teaching practices in the context of technology-enhanced learning. The systematic review focused on identifying existing teacher design work in technology-enhanced learning environments. Drawing upon the Handbook of Research Synthesis and Meta-Analysis (Cooper, Hedges, \& Valentine, 2009), the review consisted of seven stages over the research period. 
In stage one, our research team including two doctoral students in Learning Sciences identified the problem by defining variables of interest such as (1) teacher design work, (2) STEM setting, and (3) technology-enhanced learning environments. In stage two, we collected and reviewed conference papers and journal articles in the learning sciences literature (e.g., the Journal of the Learning Sciences) and design studies (e.g., Design Issues, Design Studies) using key search terms including "design thinking," "design knowledge," "pedagogical design," "curriculum design," and "teacher" AND "designer." In stage three, we devised a preliminary codebook to determine if the study included the following characteristics: (1) a focus on design work, (2) deep teacher involvement in the design work (either as a designer or as a facilitator of the design work of their students), (3) a learning environment that included technology-enhanced materials, and (4) design work that took place within a STEM context.

In stage four, we devised a more detailed codebook to code and analyze individual studies selected in stage three. This codebook asked for information about the regional context, a description of the theoretical framework that guided the design work, identification and description of the research methodology, identification of the context that design work took place in the study and the form that their design work took, identification of the parts of the design process that were articulated in the study, a description of the design work, and an identification and description of the types of supports that teachers benefited from during the design process. In stages five and six, we interpreted the cumulative evidence, and presented the synthesis, methods, and results (see details in Kim, 2015). In stage seven, we engaged decision-making audiences (i.e., teachers) in the development of the research question and synthesis protocol. Since this paper details how our research team interpreted the cumulative evidence to build a competency taxonomy of TDK, detailed information of stages five, six, and seven is beyond the scope of this paper.

\section{Competency taxonomies of teacher design knowledge}

Drawing on existing literature on teacher design work and teacher instructional design that we selected and reviewed, competency taxonomies of teacher design knowledge (TDK) consist of four main categories: data practice, design practice, knowledge creation practice, and professional teaching practice. Each of these categories is composed of a subset of four competencies (see Table 1).

Table 1 Teacher design knowledge (TDK) competency taxonomy

\begin{tabular}{|c|c|c|c|}
\hline 1. Data practice & 2. Design practice & 3. Knowledge creation practice & $\begin{array}{l}\text { 4. Professional } \\
\text { teaching } \\
\text { practice }\end{array}$ \\
\hline $\begin{array}{l}1.1 \text { Documentation of } \\
\text { available designs }\end{array}$ & $\begin{array}{l}2.1 \text { Appropriating design } \\
\text { principles through learning }\end{array}$ & $\begin{array}{l}\text { 3.1 Epistemic agency for an idea- } \\
\text { centered discourse }\end{array}$ & $\begin{array}{l}4.1 \\
\text { Adaptability }\end{array}$ \\
\hline $\begin{array}{l}1.2 \text { Creating student- } \\
\text { generated learning data }\end{array}$ & $\begin{array}{l}2.2 \text { Applying design principles } \\
\text { by teacher-researcher } \\
\text { partnerships }\end{array}$ & $\begin{array}{l}\text { 3.2 Distributed social interactions } \\
\text { for collective knowledge } \\
\text { advancements }\end{array}$ & $\begin{array}{l}\text { 4.2 Teacher } \\
\text { collaboration }\end{array}$ \\
\hline $\begin{array}{l}\text { 1.3 Manipulating and } \\
\text { analyzing student } \\
\text { learning data }\end{array}$ & $\begin{array}{l}2.3 \text { Improvising new design } \\
\text { principles in new designs }\end{array}$ & $\begin{array}{l}\text { 3.3 Collaborative formative } \\
\text { assessment for knowledge } \\
\text { creation }\end{array}$ & $\begin{array}{l}4.3 \text { Design } \\
\text { thinking }\end{array}$ \\
\hline $\begin{array}{l}1.4 \text { Visualizing student } \\
\text { learning }\end{array}$ & $\begin{array}{l}2.4 \text { Redefining design } \\
\text { principles in multiple iterations }\end{array}$ & $\begin{array}{l}\text { 3.4 Expansive learning for } \\
\text { knowledge transformation }\end{array}$ & $\begin{array}{l}\text { 4.4 Teacher } \\
\text { Leadership }\end{array}$ \\
\hline
\end{tabular}




\section{Data practice}

We define data practice as documenting, creating, manipulating, and visualizing student learning data produced, shared, and improved by the community of learners across formal and informal settings. In technology-enhanced learning environments, compared to a traditional classroom setting, a large amount of (multimodal) learning artifacts, conceptual artifacts (i.e., ideas see Bereiter, 2002), or epistemic artifacts (so-called student learning data) is produced, shared, and improved individually and collectively due to advancements in educational technologies. For example, this wealth of student learning data includes digital storytelling, drawings, photos, construction, games, and multimodal scientific models.

\section{Documenting multimodal student learning data}

Collecting data is the first step to help teachers understand student learning data which in turn better support student design work in technology-enhanced learning environments. Based on the pedagogies of relationships and listening supported by Reggio Emilia, much attention has been paid to the important role of documentation (as visible listening) in making learning visible (Rinaldi, 2001, 2006). Ontario Ministry of Education (2015) also advocated the benefits of using pedagogical documentation in making pedagogical work visible across kindergarten to grade 12 in terms of "observing, recording, interpreting, and sharing through a variety of media the processes and products of learning in order to deepen and extend learning" (Krechevsky, Mardell, Rivard, \& Wilson, 2013, p. 74). Thus, teachers need to explore diverse ways of pedagogical documentation by adapting, modifying, and/or co-designing technological tools with practitioners and researchers to listen to and collect students' progressive learning data in multimodal forms (e.g., text, photo, audio, video) as time unfolds (Buder \& Bodemer, 2008).

Teachers need to collect student learning data with regard to cognitive aspects such as interpreting, summarizing, organizing, differentiating, analyzing, evaluating, and planning. For example, in Acosta, Lui, and Slotta's (2014) study, high school teachers in Canada collected students' learning data using smart classroom technologies (called "Zydeco platform") within an immersive simulated rainforest environment (called "EvoRoom"). Throughout 10 weeks, EvoRoom curriculum activities were co-designed by researchers, programmers, and the teacher. The Zydeco platform allowed teachers to collect multimodal student learning artifacts (e.g., text notes, photos, video notes, audio notes) at the cognitive level. Students were encouraged to use evidence artifacts not only for generating and justifying their knowledge claims but also contributing to the shared evidence base within a knowledge of community. In this way, findings revealed the importance of collecting student learning artifacts generated by students in supporting collective knowledge negotiations and collective inquiry curricula.

Teachers also need to pay attention to collect student learning data at the socioemotional level such as how students feel about group cohesiveness and trust (Mullins, Deiglmayr, \& Spada, 2013). These data allow teachers to assess the quality and various levels of how students engage in group discussion to create and advance knowledge collaboratively in a knowledge society in which knowledge "is highly situated; rapidly changing; and more diverse than ever before" (Kalantzis et al., 2003, p. 16). For 
example, in Borge and Goggins's (2014) study, Yammer as the asynchronous social media platform allowed an instructor in a human-computer interaction course to collect the evolvement of the interaction patterns among college students over 16 weeks. These students' on-line discussions data collected via Yammer were also analyzed using social network analysis and communication analysis to visualize group knowledge and individual performance.

Moreover, teachers need to collect metacognitive data including how students plan, monitor, and evaluate their learning and design work (Pifarré, Cobos, \& Argelagós, 2014). In Zhang, Hong, Scardamalia, Teo, and Morley's study (2011), teachers helped elementary students reflect on and identify idea improvement opportunities while collecting formal and informal data including knowledge building portfolios written by students, emerging ideas in classroom and online, and automated feedbacks generated by learning analytics tools embedded within a collaborative online learning environment called Knowledge Forum (e.g., note contribution, semantic mapping of discourse, social networks of note reading, and building on).

\section{Creating student-generated learning data}

By expanding documenting multimodal student learning data, teachers need to adapt, modify, and/or co-design curricula and technological tools with practitioners and researchers to allow students to create multimodal student learning data beyond using the tools provided to them. For example, teachers provide students with computerized simulations of phenomena (e.g., molecular interactions, galaxy evolution) which are not accessible to our senses. Due to the growing power of technologies, in a designed virtual environment, teachers "provided learners with embodied experiences of astronomical phenomena as a driving source of experience upon which to construct models" (Kim, 2015, p. 612).

Teachers create authentic learning environments where students are encouraged to take different roles to explore and investigate multiple disciplines, perspectives, and habits of mind (Lombardi, 2007). In Lui and Slotta's study (2013), with the help of researchers and programmers, the teacher was able to situate students in an immersive tropical rainforest environment using large projection screens in a classroom. The students observed and compared the change of life forms over time individually or collaboratively. Working as "field researchers," the students explored, hypothesized, and gathered evidence about the concepts of evolutionary change that might have taken place. They also observed species, answered a set of guiding questions (e.g., What common species were found in both Sundaland and Borneo?) based on their observation, posted ideas about evolution concepts, and identified predecessors of species. These student-generated learning data were recorded and collected.

For a proper understanding of collaborative design for student learning (Ertmer et al., 2013), it is essential for teachers to understand how design takes place in the instructional design and curriculum development process. For example, in MartinezMaldonado et al.'s (Martinez-Maldonado et al., 2015) study, teachers used interactive surface devices (i.e., a multi-touch tabletop, an interactive whiteboard, a paper-based task script) and spaces (i.e., a design studio) to design and redesign the semester-long course. Such design tools were designed to allow simultaneous input from multiple 
teachers and to enhance mutual awareness and accountability of group members' actions for team-based design work. Thus, it is recommended that teachers as codesigners need to pay more attention to the larger ecology of students, learning tasks, technological tools, and artifacts, rather than simply using technological tools to create student learning data.

\section{Manipulating and analyzing student learning data}

When a large amount of multimodal learning artifacts (as student learning data) is documented and created, manipulating and analyzing the processes and products of these student learning data are of importance for teachers' design work. Learning analytics tools help the teacher manipulate student learning data at a manageable level to organize them. According to Kazmierczak (2003), as a collection of symbols/interfaces, data per se is meaningless, so data must be organized to become meaningful information (p. 46). This process includes sorting according to chronological order, filtering for semantically similar student-generated artifacts, cleaning by removing incomplete artifacts, and exporting learning artifacts to automated learning analytic tools.

For example, in the above-mentioned Borge and Goggins' (2014) study, college students' on-line postings from the Yammer were extracted and exported to excel spreadsheets aiming to explore their interaction patterns. In the spreadsheets, each original post was time stamped, and the poster was assigned by a unique ID number. As the start of a new conversation, each original poster was also sorted by a Thread ID number. Repliers were identified by new IDs and associated with the original poster's ID and the Thread ID that matched that of the original poster. This manipulation enabled the teacher to monitor and generate quantitative summaries of student contributions at both the individual level and group level.

In particular, Resendes, Scardamalia, Bereiter, Chen, and Halewood's (2015) study reported on how group-level feedback tools in Knowledge Forum allowed the teacher to help her young students (aged seven) monitor "the quantity and type of notes they wrote" in Knowledge Forum (p. 316). To promote her students' productive metadiscourse to reflect on their own and on the community's continual idea improvement (p. 310), there were two forms of group-level formative feedback in metadiscourse including (a) feedback about the group's use of domain vocabulary using a vocabulary assessment tool, and (b) feedback about types of contributions to knowledge-building discourse using an epistemic-discourse-moves tool. In particular, a semantically based social network analysis called Knowledge Building Discourse Explorer (KBDeX) was also used to examine patterns of socio-cognitive interaction. Using such new learning analytics tools, the teacher "was able to see and accomplish things that she could not accomplish without the meta-perspective provided by group-level feedback” (p. 334).

\section{Visualizing student learning}

In a technology-enhanced learning environment, the role of the teacher is to regulate student activities by (a) assessing the progress and quality of student activities at both individual and group levels, and (2) designing just-in-time interventions to offer and adapt their support, aligned to the needs of each specific group/individual student (Kaendler, Wiedmann, Rummel, \& Spada, 2015). Also, up-to-date products of student 
learning analyzed by the teacher using the technological tools (i.e., learning analytics tools) needs to be accessible to the student and their stakeholders (e.g., parents, community members, policy makers) by providing visualizations of student learning. Thus, the use of automated learning analytics (LA) tools allows teachers not only to analyze student learning data but also to communicate with students by visualizing the processes and products of student learning at both the individual level and group level (that would otherwise be hard to keep track of).

For example, Van Leeuwen, Janssen, Erkens, and Brekelmans (2015) reported on teacher use of two types of LA tools to visualize student learning, specifically focusing on cognitive activities in a collaborative setting. First, the Concept Trail visualized the discussed topics at a group's discussion by putting dots on the timeline in terms of the frequency of concepts mentioned and the concept coverage of the discussion (p. 83). The other tool is Progressive Statistics which visualized the progress of each group in terms of the number of collaboratively written words in the text editor and the chat tool. The height of bars was used to show each group's progress, and a blue line was displayed to indicate the class average. It gave a visual indication of the amount of activity within the groups to the teachers. In another study, Van Leeuwen, Janssen, Erkens, and Brekelmans (2014) also visualized whether the students in a group were in agreement or disagreement using a moving line in the side bar of the Chat windows by automatically coding students' chat utterances. This enabled teachers to see at a glance how the discussion evolved.

\section{Design practice}

While documenting, creating, analyzing, and visualizing student learning data in technology-enhanced learning environments, teachers need to continually develop and improve their understanding of the nature and process of the design of learning environments. By drawing upon the above-mentioned multiliteracies, design is viewed as a meaning-making activity (not as a finite, fixed object of esthetic consideration, see Kazmierczak, 2003) that enables re-construction or transformation of resources of the already designed world of representation (so-called Available Designs, Cope \& Kalantzis, 2000). Its approach shifts attention to the transformative process (so-called Designing) of meaning making in which teachers and students including other stakeholders (e.g., parents, community members, practitioners, policy makers) are creative designers and meaning-makers. As such, (re)designed meanings require the active participation of the teacher and the student by stressing the participatory nature of the design's mediating function to provide multimodal meaning-making opportunities.

In particular, in order to synthesize emerging design knowledge about the use of digital technologies in designing learning environments, it is recommended for teachers to improve educational practices through design-enactment-refinement iterations and learning to contextually sensitive design principles (Wang \& Hannafin, 2005), Thus, in order to continually improve classroom designs, it is essential for teachers to conduct rigorous and reflective inquiry to (a) appropriating known design principles through learning, (b) apply known and hypothetical design principles to address complex problems in real contexts in collaboration with practitioners and researchers, (c) test and define (improvise) new design principles to design innovative learning environments (in new designs), and (d) redefine design principles in multiple iterations. 


\section{Appropriating design principles through learning}

To investigate and implement innovations in technology-enhanced learning environments, teachers take advantage of appropriating known design principles developed by other researchers and teachers (Penuel \& Gallagher, 2009). As such, the Design Principles Database (Kali, 2006) was intended to help users (e.g., researchers, teachers, students in the learning sciences) publish, connect, discuss, appropriate, and review design practice and (pragmatic) design principles (with one or more features) based on collaboration among researchers and practitioners in real-world settings. The database is a set of interconnected features and design principles to synthesize and disseminate design knowledge in order to guide new designs. Features refer to any efforts and activities to use technology in terms of designed artifacts categorized as visualization tools, inquiry tools, modeling tools, collaboration tools, games, ubiquitous computing, and assessment tools (p. 189). Design principle or design pattern refers to "an abstraction that connects a feature to some form of rationale" (p. 189) behind the design of a single feature based on various design-based research projects. Each feature is linked with a Specific Principle, and specific principles are linked between themselves in Pragmatic Principles which are synthesized and abstracted as Meta-Principles.

For instance, in Kali's (2008) study, to design a new peer-evaluation activity building on the existing body of knowledge, the author as an instructor in an undergraduate level philosophy of education course used the Design Principles Database. Since there were no available design principles for peer-evaluation at that time in the database, she reviewed existing empirical studies in the field of peerevaluation and abstracted these pragmatic design principles to enable her preservice students to give feedback to their peers: (a) involve students in developing the evaluation criteria for the peer-evaluation, (b) enable anonymity to avoid bias in peer-evaluation, and (c) make the synthesis of the peer-evaluation results visible for learners. In order to explore the challenges of the design of the online peerevaluation activity in the specific context, three design-enactment-refinement iterations were followed in new contexts. From the design iterations, empirical outcomes were explicitly translated into new features and Specific Design Principles. Furthermore, new theoretical knowledge (as practical design knowledge) about issues of bias and objectivity in peer-evaluation activities was created. Such additional practical design knowledge was synthesized with the existing knowledge in the database.

In this way, pre-service students in Kali's (2008) study appropriated Specific Design Principles through learning a detailed description of the functionality of the feature with a very specific context, and the specific principle and rationale behind the design. They also understood Pragmatic Design Principles through learning a detailed description of the Specific Design Principle, theoretical background to understand the overarching rationale behind the design, and tips for designers including limitations, trade-offs, and pitfalls for designing with the principle in the specific context. In Yoon et al.'s (2015) study, in-service teachers also participated in 40-h face-to-face professional development activities where they learned and articulated design features for teaching and learning complex systems using StarLogo models in high school science classroom contexts. 


\section{Applying design principles by teacher-researcher partnerships}

In collaboration with researchers, practitioners, and/or more experienced teachers, teacher knowledge of design principles and features with technological affordances can be further supported by applying learned design principles (as above-mentioned "Available Designs," Cope \& Kalantzis, 2000) to address complex problems in new contexts. In Teo's (2014) study, with the aim of acculturating teachers into the school-wide knowledge-building community initiated by researchers, teachers who had more than 5 years of knowledge building (KB) experience and those who had less than 2 years of $\mathrm{KB}$ experience in a primary school met weekly to discuss emerging complex problems of knowledge building (design) principles, pedagogies, and technological affordances. They shared their practice and discussed how to adapt knowledge building (design) principles in their classrooms. For example, they discussed how they could guide students' inquiry-based learning not only to meet content standard demands but also to promote student-generated questions. They also investigated how to use features of Knowledge Forum (an online forum) as a technological support with the aim of helping students engage productively in improvable and continual idea improvement relevant to knowledge building principles (see Scardamalia \& Bereiter, 2006).

For example, Haslir, Lee, Mohd, and Ling (2016) investigated how a teacher developed and modified the classroom design on the topic of "Food Matter" through the use of the Knowledge Building (KB) Principles (see Scardamalia \& Bereiter, 2006) over a 5-week period in Singapore. In line with KB principles of real ideas and authentic problems, the teacher tried not to dictate the content so as to ensure his students to generate their ideas about food. As a result, many interesting questions were generated by his students, for example, "how is food important?" and "how is food made/created?" These questions were captured by the teacher on the whiteboard. With another KB principle of constructive use of authoritative sources in mind, he also designed trigger activities such as experiments on food testing and soil acidity. His students discussed about these experiments through making connections with what they had learned in previous lessons. To extend discourse in class, the teacher created the first Knowledge Forum as a collaborative online platform to help his students transit their classroom discussions seamlessly to the online platform where their ideas could be improved continually. In this way, through the use of the design principles, the teacher co-participated in the knowledge building processes with his students, reflected on the process, and enabled and facilitated KB discourse, rather than simply following predetermined scripts and procedures (Sawyer, 2011).

\section{Improvising new design principles in new designs}

In addition to applying and adapting available design principles and features to their local circumstances, teachers improvise design principles to advance pedagogical understanding and decision-making in the specific context. However, the teacher's improvisation of design principles rarely becomes engrained in common teaching practice. A related challenge may be that teacher education programs and teacher professional learning in most countries devote relatively little time to developing teacher design expertise beyond lesson planning (McKenney et al., 2015). Improvisation of design 
principles requires sufficient time to have a long-term partnership between teachers and researchers as experts in design-based research.

For example, in Lee, Kim, Kim, and Lee's (2012) study, to further elaborate challenging pedagogical, curricular, and technological issues relevant to promoting dialogic practice in a high school geography curriculum, teachers actively engaged in curriculum design (i.e., inquiry-based geography curriculum), technological tool design (i.e., game), and pedagogical design (i.e., game-based learning). In particular, by creating and testing teaching designs through design-enactment-refinement iterations over 3 years in collaboration with researchers and practitioners (i.e., game designers, paleontologists, geologists) in a research team, teachers continually engaged in the sustained cycles of principle-based understanding, design, and reflection. As a result of reflective and rigorous collaborative inquiry, there were the six contextually sensitive design principles of dialogic practice: engage students in group activities, start with open-ended questions, engage them in activities that provide relevant experience, require them to produce group or individual artifacts, develop a sharing mechanism of the class, and engage them in consolidation and linking activities.

\section{Redefining design principles in multiple iterations}

Teachers are expected to not only improvise but continually improve and redefine design principles derived from the specific context, with this process supported through use of knowledge networks to advance pedagogical understanding and decisionmaking. It is of importance for teachers to understand that as a kind of conceptual artifacts (Bereiter, 2002), their design and practice can always be improved and even yield new knowledge. Multiple iterations leading to improving outcomes are highlighted in design-based research (The Design-Based Research Collective, 2003). This requires a simultaneous process of problem formulation and solution generation (Cross, 2001) involving numerous routine design practice (McKenney et al., 2015) with multiple iterations of designing, implementing, and redesigning technology-enhanced learning (or pedagogical design) over a long period of time in various contexts.

For example, Law, Yuen, and Tse (2012) described how a grade 7 science teacher developed her deeper understanding of knowledge building (KB) design principles to tackle authentic problems over three years. During her first year of teaching, she simply assigned existing textbook questions to her students in online discussions without being aware of the difference between these questions and questions that students cared about. In the second year, she posed some paradoxical questions to help her students clarify common misconceptions. However, there were still very few students who actively engaged in the online discussions. In the third year, supported by university researchers, the teacher gradually released control of the learning goals and processes to her students through the process of collaborative inquiry. She became confident and comfortable to open up online space to have her students explore questions that they were genuinely interested in.

Drawing on her understanding of KB design principle of real ideas/authentic problems, the teacher also provided her students with authentic learning contexts including a field trip, experiments, and online simulations. Also, she guided her students to generate authentic questions and ideas that could be further advanced through 
collaborative inquiry. Thus, as the teacher developed socio-technical designs for engaging her students in authentic questioning and collaborative inquiry, there were increasing levels of agency exercised by both the teacher and her students. In other words, there was a visible increase in agency at all levels of the learning network including students, teachers, and school senior management, "resulting in deepening levels of pedagogical innovation over time, as well as changes in governance in response to the innovation as a result of self-organization" (Laferrière, Law, \& Montane, 2012, p.148). There were emergent features of learning networks: (a) the Professional Network for KB in her school where other teachers also collaborated supported by her principal, and (b) the Knowledge Building International Project (KBIP, see Laferrière et al., 2012) where K-12 teachers and school leaders from several countries co-designed the sociotechnological environment for technology-enhanced learning environments.

\section{Knowledge creation practice}

In line with the current view of learning as participation in particular sociocultural contexts (Sfard, 1998; Wenger, 1998), knowledge is no longer viewed as an individual static entity. Rather, in the knowledge age, knowledge creation is inherently social (Csikszentmihalyi, 1999; Sawyer, 2004, 2007; Valsiner \& Veer, 2000). Also, the importance of constructive dialog or collaborative knowledge-creating discourse is well recognized in knowledge creation practice (Van Aalst, 2009). In other words, much of what has been emphasized in current knowledge creation practice is the shift from a focus on individual communicative behavior to community interchanges, connected discourse (Bereiter, 2010), and collective cognition (Chan, 2013). Thus, teachers need to focus more on supporting students in participating in various phases of the design and development of the educational innovation. In particular, the participatory design approach can be a mechanism for knowledge creation practice in which all students as epistemic agents generate and identify promising ideas and continually improve the ideas through sustained collaborative inquiry and discourse. To advance the knowledge of the community, there are the following four knowledge practice taxonomies in alignment with the above-mentioned data practice and design practice.

\section{Epistemic agency for an idea-centered discourse}

As described above in the data practice, teachers need to listen to diverse voices (called multivoicedness, see Wertsch, 1993) and ideas of students in order to keep all students engaged deeply and meaningfully in continuous improvement of ideas by comparing and combining diverse ideas. According to Zhang, Scardamalia, Reeve, and Messina (2009), ideas are equivalent to "theories, intentions, models, plans-the intellectual life of the community-are accessible as knowledge objects to all" (p. 9), not personal knowledge or beliefs.

Research by Matuk and Linn (2014) showed how the Idea Manager embedded in the open online learning environment (called Web-based Inquiry Science Environment) enabled teachers to monitor students' knowledge integration as they generated, distinguished, and reconciled their multiple and often contradictory ideas.

In Scardamalia's (2002) study, grade 1 students explored why leaves change color in the fall and shared diverse ideas in Knowledge Forum (a collaborative online platform). 
Example ideas are: "Fall-I think the chlorophyll goes into the tree to keep warm for the winter." "I think leaves change color because when the leaf falls down I think that the chlorophyll goes to the outside of the leaf so it leaks off the leaf.", and "Because it's too cold for the chlorophyll to make food for the tree." (p. 80). By appropriating and synthesizing these diverse ideas, students and their teacher worked together to create their collective note (called a "rise-above" note) in Knowledge Forum: "These notes share the idea that the sap gets plugged and that is why the leaves change color." Thus, by prioritizing student voice in a culture of learning, the teacher allowed students to take ownership and responsibility of their learning leading-that is epistemic agency -to collective knowledge advancement.

Teachers need to provide students with hands-on (e.g., field trips, virtual tours) and safe learning environments so that students can use real-life experiences outside school and develop a depth of understanding by making their ideas explicit, know alternatives ideas, negotiate dissonance, and refer to authoritative resources to support their ideas. For instance, due to the maple syrup production field trip in Scardamalia's (2002) study, student knowledge was advanced through experiments and field trips. Some students initially believed that the leaves change color because the chlorophyll goes into the tree trunk to keep warm. However, their observation of the sap made students critically reflect on their own and on the classroom community's understanding. They also considered how to advance their ideas and understanding toward deeper explanations and higher level conceptualization.

To foster epistemic agency as the individual and collective responsibility for continual idea improvement, in Resendes et al.'s (2015) study, the teacher along with researchers provided grade 2 students in an experimental group with two group-level formative feedback visualization tools during teacher-student discussion time in Knowledge Forum. One of the tools is Comparative Word Clouds which visualized the comparison between domain-specific words the students used in their Knowledge Forum notes and words used by writers more knowledgeable in the field. The other tool is Epistemic Discourse Moves Tool which displayed the frequencies of discourse moves indicated by students' use of epistemic discourse markers known as KB scaffolds (e.g., "I need to understand ...," "My theory ...," "Important information + Source ...," "This information is important because ...") in Knowledge Forum. The teacher and researchers co-designed and used these learning analytics tools to help the students reflect on vocabulary use and discourse patterns and further elaborate and explain their understanding which was applicable to real-world outside of school. As a result, using these visualization tools, the teacher encouraged students to reflect on and evaluate their own and their group's knowledge progress and discursive practices by carrying on productive metadiscourse. Thus, the teacher effectively facilitated students' vocabulary knowledge in terms of broadening domain-specific vocabulary, more problem-centered discourse moves requiring formulation of questions and explanations (Chan, 2001), scientific understanding, epistemic complexity of ideas, and interpersonal connectedness of online discourse.

\section{Distributed social interactions for collective knowledge advancements}

The importance of all students as epistemic agents taking collective responsibility for sustained, collaborative knowledge advancement has been recognized in the 
collaborative learning literature (Kreijns, Kirschner, \& Jochems, 2003; Scardamalia, 2002; Stahl, Koschmann, \& Suthers, 2006). In line with the emergent process of knowledge creation (Roth \& Bowen, 1995; Sawyer, 2007), research by Zhang et al. (2009) showed the need for more distributed, flexible, and adaptive social structures in promoting dynamic, opportunistic, and community-wide collaboration among grade 4 students.

In a 3-year design experiment, the teacher worked with researchers to promote collective responsibility for community knowledge. To assess collective cognitive responsibility for sustained community knowledge, two issues of knowledge diffusion (i.e., idea spread) and depth of understanding (i.e., epistemic complexity, scientific sophistication) were analyzed in the study. In the first year, students were divided into six groups based on their interests to understand optics. Because of the fixed small-group structure, most students only read KF notes in the views of their own groups. To maximize opportunities for collective responsibility for community knowledge, in the second year, the teacher coordinated the fixed small groups with substantial cross-group knowledge sharing. In the third year, distributed and opportunistic collaboration was encouraged to advance their understanding of optics with small teams forming and disbanding at the volition of community members. By recognizing emerging goals, all students became more responsible for community knowledge, and actively participated in knowledge advancement and dynamic diffusion of information among students, giving rise to a higher level of collective responsibility. Relative to year 1 and year 2, year 3 showed more direct student collaboration and less mediated by the teacher, indicating distributed collaboration and collective engagement. Compared to centralized, rigid, and fixed small-group collaboration, opportunistic collaboration through the distributed, flexible social interactions in year 3 allowed students to generate diverse inquiries and rise above this diversity to produce more coherent, sophisticate, and interconnected explanations.

\section{Collaborative formative assessment for knowledge creation}

In line with evolving conceptions of learning and knowledge, it is essential for teachers to engage in formative assessment to monitor and assess each student's strengths and needs and then (re)design instruction to support student learning continually (Bell \& Cowie, 2001; Mislevy \& Haertel, 2006; Pellegrino, 2014; Wiliam \& Thompson, 2007). According to Atkin, Black, and Coffey's (2001) formative assessment model, effective teachers encourages students to reflect on these questions: (a) Where are you trying to go? (b) Where are you now? (c) How can you get there? Compared to the traditional notions of assessment, assessment has increasingly been regarded as integral part of teaching and learning (Sadler, 1989; Shepard, 2000; Wilson, 2004). However, teachers often view assessment as something apart from teaching and learning, serving primarily the purpose of assigning grades against predetermined standards. Further, it is challengeable for teachers to assess both individual and collective knowledge advancement because existing assessment primarily focus on individual learning processes and capture very little of the sustained knowledge advancement and knowledge transformation.

To respond to this challenge, recent research on collaborative knowledge building explores the design of formative assessment supported by automated analyses technology 
embedded in collaborative online platforms such as Knowledge Forum for making collective knowledge progress visible (van Aalst \& Chan, 2007). In particular, research by Chen and Zhang (2016) shows key design principles of assessment for sustained knowledge building including (a) student-directed assessment with high-level collective responsibility for high-level decisions including setting goals (what should be investigated), long-range planning (what further actions should be carried out based on the results of the assessment), and progress tracking (what should be assessed, based on what evidence); (b) collaborative assessment of collective knowledge advancements in relation to personal knowledge advancements based on ongoing discourse and student artifacts; (c) formative and transformative assessment to provide ongoing feedback to support sustained idea improvement and scaffold future learning; and (d) technology-supported assessment using analytic tools to analyze rich data and provide easily interpretable results and visualizations.

Guided by these principles, the authors designed collaborative formative assessment in grade 6 classrooms for sustained knowledge building supported by a timeline-based collective discourse mapping tool called "the Idea Thread Mapper" (ITM) embedded in Knowledge Forum. A science teacher in the study implemented ITM to support collective metadiscourse in Knowledge Forum notes and responses and reflection among students by identifying clusters of shared, high-interest themes of inquiry (called "idea threads" as the assessment focus) displayed on a timeline. Based on the shared focal themes of inquiry, the students formed into groups as emerging subsets of the members of a community, and they started to collect assessment evidence by examining identified important KF notes using ITM.

In each idea thread, each group also coauthored and synthesized the big ideas using ITM's Journey of Thinking feature consisting of three reflection sections: "We want to understand," "We used to think ..., and we now understand ...," and "We need to do more." Supported by the teacher, students examined ITM to assess their collective knowledge advancement evidenced through sustained and progressive discourse contributions in the community's online discourse. They also used social network graphs to assess their social dynamics of collaboration, and wrote portfolio notes to assess student personal understanding from the whole community's work informed by the collaborative assessment. Based on this ITM-aided collaborative, formative assessment, the teacher allowed students to monitor and deepen their collective inquiry through generating more explanationseeking and idea-deepening questions without causing much additional work among students. Students improved a reflective awareness of the important inquiry themes and discourse contributions. Such ongoing collaborative formative assessment also enhanced teacher engagement in a more coherent flow of the assessment activities. Automated analysis in ITM assisted the teacher to monitor collective knowledge through collecting and interpreting evidence of idea contributions, advancement, and collaboration. This assessment supported teacher efforts to generate ongoing feedback to address students' deeper needs and gaps of knowledge through further inquiry. Thus, collaborative formative assessment involved both the teacher and students in knowledge creation.

\section{Expansive learning for knowledge transformation}

The global shift to the knowledge society (Drucker, 1993) or the creative economy (Florida, 2002) in the twenty-first century requires the rethinking of the traditional 
vision of learning called instructionism (Papert, 1993) or a transmission and acquisition conception of learning (Rogoff, 1990) in which a knowledgeable teacher transmits knowledge as a collection of facts and procedures, and a learner acquires that knowledge. In the late 1980s, learning sciences researchers began to argue that knowledge is not just a static mental structure inside the learner's head, but a situated (and embodied) view (Greeno, 2006; Rogoff, 1998) that accounts for both the agency of the learner as the knowledge producer and participation in collaborative activity, not about isolated individuals. Thus, the goal of teaching becomes to better understand the social and cognitive processes in a particular sociocultural context to support deep student learning such as generating new ideas, new theories, new artifacts, and new knowledge. Further, the teacher needs to use this knowledge to redesign other learning environments resulting in alternative models of learning including new curricular materials, new collaborative activities, and innovative educational software (Sawyer, 2007).

Thus, there has been increasing interest in the theory of transformative learning in the field of teacher education. For example, according to the Association of Canadian Deans of Education (2006), educators need to demonstrate the transformative power of learning for individual students and their communities. Transformative learning approaches require teachers to go beyond transmitting information and knowledge. For this process to occur, the involvement of the collective design effort is essential. In recent years, design-based research within the learning sciences takes the agency of the learners as a foundational point of departure in this transformative learning that emphasizes personally significant learning, resulting in the transformation of the learner's existing knowledge, learners themselves, and their social and cultural environments.

For example, Sannino, Engeström, and Lemos' (2016) work on expansive learning argued that both teachers and students need to carry out collaborative inquiries and transform the object of their activity for developing new solutions, leading to new, expanded forms of activity as "design emerges out of collective analyses of the historical contradictions, current disturbances, and possible alternative features of the activity in question" (p. 32). The collaborative design effort is regarded as part of an expansive learning process, involving reconceptualization and practical transformation of the object of the learners' activity. Referred to as design-based implementation research, formative interventions (called the Change Laboratory), or networked improvement communities (McKenney, 2018), such efforts are referred to as "intraventions" (Sannino et al., 2016, p. 600) in which although researcher-interventionists are part of the expansive learning process, "their role is to intervene by provoking and supporting the process led and owned by the learners" in wider communities and work settings (p. 600).

Expansive learning and transformative agency are pursued through formative interventions based on two epistemological principles: (a) double stimulation identifying conflicts of motives triggered by problematic situations (as the first stimuli) and developing agency with the help of the second stimuli to cope with and transform the problem; and (b) ascending from the abstract to the concrete involving practical experimentation to open up "rich and diverse possibilities of explanation, practical application and creative solutions" (p. 605). 


\section{Professional teaching practice}

The concept and practice of "teacher professionalism" has gained increasing attention in recent years. What are shared understandings regarding teacher professionalism in technology-enhanced learning environments? Although the teacher is regarded as the most important individual in the field of education, there remains an uncertainty of what comprises "professional" teaching. Depending on the educational context, the concept of teacher professionalism may evoke many images and have multiple definitions. Thus, in alignment with the above-mentioned data practice, design practice, and knowledge practice, there are four taxonomies in teacher professionalism: (a) Adaptability, (b) Teacher Collaboration, (c) Design Thinking, and (d) Teacher Leadership.

\section{Adaptability}

There is increasing evidence that "adaptivity of teacher regulation, in terms of welltimed and well-chosen teacher interventions" (van Leeuwen, 2015, p. 139) can increase student engagement and co-construction of knowledge. However, research also shows that it is a challenge for the teacher to become adaptive to design just-in-time interventions, aligned to the needs of each student when attempting new, innovative practices (Brown \& Edelson, 2003; Darling-Hammond, Hammerness, Grossman, Rust, \& Shulman, 2005) toward productive adaptation (DeBarger, Choppin, Beauvineau, \& Moorthy, 2014). Increasingly, the concept of adaptive expertise is used to demonstrate high degrees of both efficiency and innovation to explain teacher professionalism within learning environments (Crawford, 2007; Lin, Schwartz, \& Hatano, 2005; Penuel \& Gallagher, 2009). Adaptive expertise can be compared with routine expertise demonstrating high efficiency but low innovation (Hatano \& Inagaki, 1986). Schwartz, Bransford, and Sears (2005) graphically illustrated adaptive experts as high degrees of efficiency and innovation, routine experts as high efficiency but low innovation, and novices as high innovation but low efficiency.

Further, De Arment, Reed, and Wetzel's (2013) study investigating adaptive expertise in teaching articulated key adaptive dispositions, metacognitive skills, and cognitive skills. Adaptive dispositions include (a) maintaining an epistemic distance between prior knowledge and current problem; (b) viewing world as complex, irregular, and dynamic; (c) willing to reveal and work at limits of knowledge and skill; and (d) focusing on learning rather than merely applying knowledge. Metacognitive skills are (a) questioning current levels of expertise and monitoring own learning, (b) considering feedback from others about problem-solving and outcomes, (c) monitoring own results and performance, and (d) explaining decisions and justifying outcomes of metacognitive process. Cognitive skills are (a) thinking flexibly based on student characteristics and others' perspectives, balancing efficiency and innovation, (b) developing causal models based on contributing factors, (c) reasoning based on hypotheses and data, and (d) explaining decisions and justifying outcomes of cognitive process. Aligned to these key tenets of adaptive expertise, the authors proposed reflection prompts to support guided, critical, and justificatory discourse between teacher candidates and teachers.

Brown and Edelson's (2003) case study described how a teacher adapted the intended curriculum to meet the needs of her students in a 10-week inquiry-based classroom science project, the global warming project. Instead of sticking to the intended curriculum 
co-designed with researchers, the teacher flexibly adapted the curriculum to engage her students in a Sun-Earth modeling activity by making their own models. The students used penlights and graph papers to build a model of the Earth-Sun relationship in order to understand the angle of incidence. Her curriculum adaptation was based on manipulating and analyzing student learning data in terms of data practice. By monitoring student learning outcomes and considering feedback from her students, the teacher aimed to engaging her students in a creative process and to promote their scientific understanding through model-based inquiry.

In Lee, Chan, and van Aalst's (2006) study, as a teacher who developed instructional approaches for 8 years based on knowledge building in his Visual Arts course, Lee adapted knowledge building design principles in order to address the needs of his students with low academic achievement. To support his students' interpretation of texts, he used the affordances of multimodal resources using videos and photographs in the curriculum. The teacher intentionally created a safe learning environment to make all students feel comfortable to share their ideas and become motivated to sustain their interests and improve their ideas. Also, the teacher flexibly adapted asynchronous online posting in Knowledge Forum to synchronous paper-based posting, so his students actively wrote and shared their ideas on cards. Further, aligned to key design principles of knowledge building, the teacher also created the physical and visual KB Wall as a public space where student idea cards were posted and connected by strings for collaborative whole-class discourse.

\section{Teacher collaboration}

In the past two decades, there has been a growing number of studies recognizing the importance of teacher collaboration for professional teaching practice. Researchers have investigated the impact of teacher collaboration including peer collaboration (Sparks, 2002), peer assessment and feedback (Gosling, 2015; Ronfeldt, Farmer, McQueen, \& Grissom, 2015), peer coaching and mentoring (Little, 2005), and team teaching (Vangrieken, Dochy, Raes, \& Kyndt, 2015). Also, as mentioned above in Design Practice, and Knowledge Creation Practice, teacher collaboration occurs in many forms such as building a partnership with researchers by participating in design-based research, and mutual learning processes in design-centric partnerships (McKenney, 2018).

In particular, toward scalable learning, professional learning communities (PLC, see Stoll, Bolam, McMahon, Wallace, \& Thomas, 2006) have been considered as an effective social learning environment, rather than individual, isolated professional development. In particular, researchers have investigated building long-term partnerships with (teacher) practitioners and researchers in terms of research-practice partnership (RPPs) (Coburn \& Penuel, 2016; Penuel \& Gallagher, 2017). RPPs aim to improve stakeholder interaction and the flow of new knowledge in and across educational systems to foster educational improvement. RPPs can be characterized by collaborative models of research-practice interactions that emphasize "the multidirectional flow of knowledge between researchers and practitioners, each of whom brings his or her own values and perspectives while working on a shared goal" (McKenney, 2018, p. 5). Thus, teachers need to be actively involved in collaborative inquiries into their own practice and transform the objects of their activity toward expansive learning for knowledge transformation. 
For example, research conducted by Johnson, Severance, Leary, and Miller (2014) described this collaborative model of research-practice interactions among diverse stakeholders including mathematics teachers, university researchers, ministry administrators, school district curriculum supervisors, web engineers, and parents, aiming to adapt an Algebra 1 curriculum to meet the objectives of the Common Core State Standards. Instead of the unidirectional flow of knowledge from researchers to teachers, all stakeholders brought their own values and perspectives on the mathematical tasks. The teachers showed the desire to adapt mathematical tasks and resources to meet their teaching practice and the needs of students. The curriculum supervisors considered the mathematical tasks as vehicles to add cognitive demands into the curriculum, and were reluctant to encourage teachers to modify mathematical tasks. The university researchers highlighted the importance of a set of design principles which could be applied to all mathematical tasks. The web engineers interpreted mathematical tasks as digital resources. They jointly analyzed such dynamic and unpredictable deep-seated contradictions in mathematical tasks and explored solutions collectively with the help of the multidirectional flow of knowledge among diverse stakeholders.

\section{Design thinking}

The ability to empathize, think creatively, collaborate productively, experiment with solutions, and communicate ideas are all key parts of design. Thus, to support teacher collaboration, design thinking is also essential in professional teaching practice. Design thinking is generally defined as "an analytic and creative process that engages a person in opportunities to experiment, create and prototype models, gather feedback, and redesign" (Razzouk \& Shute, 2012, p. 330). Design process usually starts with dissatisfaction with current state of things and a determination that some action needs to be taken (Razzouk \& Shute, 2012). Design thinkers not only think about how a design/ product work but also take action to design and construct models or prototypes to bring their abstract ideas to more concrete forms. By exploring, constructing, and revising their concrete models or prototypes, design thinkers continuously explore, test, visualize, and evaluate their conceptual ideas (that are not otherwise possible). This design thinking process is characterized as interactive, exploratory, and even chaotic (Braha \& Reich, 2003). What needs to be highlighted of the characteristics of design thinkers is that they look at multiple solutions to a problem and always keep a systemic version of the whole picture (Razzouk \& Shute, 2012).

According to the Institute of Design at Stanford (2010), design thinking process has five stages to promote a designerly mindset (Cross, 2001): Empathize, Define, Ideate, Prototype, and Test. As a design thinker, to create meaningful innovations, the teacher must gain empathy for students and what is important to them. To emphasize, the teachers need to observe, engage, and watch and listen to what their students do in relevant contexts. After gaining invaluable empathy for the students, in the Define mode of the design process, the teachers are required to define a meaningful and actionable problem statement by synthesizing collected information in the empathize mode to discover connections and patterns. In order to transit from identifying problems to create solutions for the students, the teachers need to generate the broadest range of possibilities using ideation techniques such as bodystorming, mindmapping, 
and sketching without the evaluation of generated ideas. To manage the solutionbuilding process, the teacher is recommended to create low-resolution prototypes that are quick and cheap to make but can elicit useful feedback from the students. The test mode is another opportunity to understand the students and refine prototypes and solutions to inform the next iterations of prototypes.

\section{Teacher leadership}

In the past two decades, the importance of teacher leadership has been increasingly recognized in professional teaching practice (Hunzicker, 2012; York-Barr \& Duke, 2004). Sinha and Hanuscin's (2017) case study investigated the process and pathways of leadership development of three high school science teachers with varying years of teaching experience as they participated in the same professional development program (PD). They defined a teacher leader as "one who not only engages in the practice of leadership, but who also identifies his/herself as a teacher leader" (p. 357). Drawing upon York-Barr and Duke's (2004) review on teacher leadership, seven dimensions of teacher leadership practices were examined: (a) coordination and management, (b) school or district curriculum work, (c) professional development of colleagues, (d) participation in school change and improvement initiatives, (e) parent and community involvement, (f) contributions to the profession of teachers, and (g) pre-service teacher education. In regard to teacher leadership views, three teacher participants initially held views of leadership as a formal position in terms of positional and hierarchical conceptions of leadership. Due to the PD experiences, however, they changed their conceptions of leadership. They viewed leadership as title independent and ended up recognizing themselves as leaders as they gained confidence due to success in their various teacher leadership roles and activities. In addition to her/his self-perception, feedback, recognition, and support from colleagues and PD staff were crucial to the teacher's identity development.

All three teachers developed as leaders by expanding their repertoire of leadership activities including personal growth and development (e.g., pursuing graduate level coursework, interning with the principal, reading leadership literature, taking firm steps to improve teaching skills such as videotaping their own teaching) (p. 366). Although regardless of their years of service, all three teachers initially held very similar views of teacher leadership, the experienced teacher, compared to newer teachers, started leading outside his classroom and school. Further, each teacher found her/his own leadership activities related to PD of colleagues depending on the interests and needs of the teacher and her/his context. Based on these findings, the process of teacher leadership development is viewed as "a synergistic interplay of an individual's views of leadership, engagement in leadership practices and identity development" (p. 368). The model implies that supportive school contexts and PD programs are crucial to allow teachers to transform their leadership views (i.e., defining teacher leadership), identify their leadership opportunities in their day to day practices to expand their leadership practices, and eventually develop their leadership identity. In other words, instead of a predetermined pathway for teacher leadership development, teacher educators and professional developers need to provide flexible programs to accommodate individual teachers' contexts, personal leadership development priorities, and career stage. 


\section{Conclusion and implications}

Although teacher design knowledge is a complex phenomenon (McKenney et al., 2015), there is little literature on defining a shared language to communicate core concepts of teacher design knowledge. Drawing upon current educational efforts in line with the increasingly design nature of STEM teaching and learning, this systematic review investigated the taxonomy of TDK competencies to make TDK processes visible both the STEM teacher educators and the STEM teachers. As Table 1 indicates, there are four TDK practices: (a) Data Practice, (b) Design Practice, (c) Knowledge Creation Practice, and (d) Professional Teaching Practice. Each practice has four taxonomies to elaborate concepts that teachers as designers employ as they design technologyenhanced curricula.

Also, proposed TDK competency taxonomies can suggest particular teacher roles corresponding to taxonomies of integrated TDK practices. For example, documenting multimodal student learning data in Data Practice, appropriating design principles through learning in Design Practice, epistemic agency for an idea-centered discourse in Knowledge Creation Practice, and adaptability in Professional Teaching Practice represent teachers as listeners. In this sense, teachers are viewed as collaborators by creating student-generated learning data in Data Practice, applying design principles by teacherresearcher partnerships in Design Practice, distributed social interactions for collective knowledge advancements in Knowledge Creation Practice, and teacher collaboration in Professional Teaching Practice. Teachers are also considered as innovators by manipulating and analyzing student learning data, improvising new design principles in new designs, collaborative formative assessment for knowledge creation, and expansive learning for knowledge transformation. Finally, teachers are viewed as leaders by visualizing student learning, redefining design principles in multiples iterations, expansive learning for knowledge transformation, and leadership.

These taxonomies aim to promote the use of pedagogical patterns that consists of specific elements and scaffolds that would guide teachers through the design process. As this work advances, a design language and format could be provided where the multiple levels and facets of designs are described, specified, and communicated, and would help guide the pedagogical design decisions of teachers.

\section{Abbreviations}

STEM: Science, Technology, Engineering and Mathematics; TDK: Teacher design knowledge

Acknowledgment

As a Principle Investigator, I am grateful for the support from Social Science and Humanities Research Council of Canada and University of Western Ontario in funding this project.

Authors' contributions

MSK participated in data collection and analysis including writing and approving the manuscript for submission.

Funding

Funding from Social Science and Humanities Research Council of Canada and University of Western Ontario.

Availability of data and materials

Please contact the author for data requests. 
Received: 26 May 2019 Accepted: 15 October 2019

Published online: 21 November 2019

\section{References}

Acosta, A., Lui, M., \& Slotta, J. (2014). Exploring group-level epistemic cognitions within a knowledge community and inquiry curriculum for secondary science. In Proceedings of the 11th International Conference of the Learning Sciences (ICLS). Boulder: International Society of the Learning Sciences (ISLS). (pp. 673-680).

Atkin, J. M., Black, P., \& Coffey, J. (2001). Classroom assessment and the national science standards. Washington, DC: National Academies Press.

Barab, S. A., Hay, K. E., Barnett, M., \& Squire, K. (2001). Constructing virtual worlds: Tracing the historical development of learner practices. Cognition and Instruction, 19(1), 47-94.

Bell, B., \& Cowie, B. (2001). Formative assessment and science education. Dordrecht: Kluwer Academic Publishers.

Bereiter, C. (2002). Education and mind in the knowledge age. Mahwah: Lawrence Erlbaum Associates.

Bereiter, C. (2010). How to make good knowledge-building discourse better. In Keynote address at the 2010 knowledge building summer institute. "New assessments and environments for knowledge building", Toronto, Canada, August 3-6, 2010.

Borge, M., \& Goggins, S. (2014). Towards the facilitation of an online community of learners: Assessing the quality of interactions in yammer. In Proceedings of the 11th ICLS. Boulder: International Society of the Learning Sciences ISLS. (pp. 753-760).

Braha, D., \& Reich, Y. (2003). Topological structures for modeling engineering design processes. Research in Engineering Design, 14, 185-199.

Brown, M., \& Edelson, D. (2003). Teaching as design: Can we better understand the ways in which teachers use materials so we can better design materials to support their change in practice? (Design Brief). Evanston: Center for Learning Technologies in Urban Schools.

Buder, J., \& Bodemer, D. (2008). Supporting controversial CSCL discussions with augmented group awareness tools. International Journal of Computer-Supported Collaborative Learning, 3(2), 123-139.

Chan, C. K. K. (2001). Peer collaboration and discourse patterns in learning from incompatible information. Instructional Science, 29(6), 443-479.

Chan, C. K. K. (2013). Collaborative knowledge building. Towards a knowledge creation perspective. In C. E. Hmelo-Silver, C. A. Chinn, C. Chan, \& A. M. O'Donnell (Eds.), The international handbook of collaborative learning (pp. 437-461). New York: Routledge.

Chen, J., \& Zhang, J. (2016). Design collaborative formative assessment for sustained knowledge building using idea thread mapper. In Proceedings of the 12th International Conference of the Learning Sciences (Vol. 1). Singapore: International Society of the Learning Sciences. (pp. 647-654).

Coburn, C. E., \& Penuel, W. R. (2016). Research-practice partnerships in education: Outcomes, dynamics, and open questions. Educational Researcher, 45(1), 48-54.

Cooper, H., Hedges, L. V., \& Valentine, J. C. (Eds.). (2009). The handbook of research synthesis and meta-analysis. New York: Russell Sage Foundation.

Cope, B., \& Kalantzis, M. (Eds.). (2000). Multiliteracies: Literacy learning and the design of social futures. London: Routledge.

Crawford, V. M. (2007). Adaptive expertise as knowledge building in science teachers' problem solving. In Proceedings of the European cognitive science conference (pp. 250-255). New York: Lawrence Erlbaum Associates.

Cross, N. (2001). Designerly ways of knowing. Design Issues, 17(3), 49-55.

Csikszentmihalyi, M. (1999). Implications of a systems perspective for the study of creativity. In R. J. Sternberg (Ed.), Handbook of creativity (pp. 313-335). Cambridge: Cambridge University Press.

Darling-Hammond, L., Hammerness, K., Grossman, P., Rust, F., \& Shulman, L. (2005). The design of teacher education programs. In L. Darling-Hammond \& J. Bransford (Eds.), Preparing teachers for a changing world: What teachers should learn and be able to do (pp. 390-441). San Francisco: Jossey-Bass.

De Arment, S. T., Reed, E., \& Wetzel, A. P. (2013). Promoting adaptive expertise: A theoretical framework for special educator preparation. Teacher Education Special Education, 36, 213-226.

DeBarger, A., Choppin, J., Beauvineau, Y., \& Moorthy, S. (2014). Designing for productive adaptations of curriculum interventions. In B. J. Fishman, W. R. Penuel, A. R. Allen, \& B. H. Cheng (Eds.), Design-based implementation research: Theories, methods, and exemplars (pp. 298-319). New York: Teachers College Press.

Drucker, P. F. (1993). Post-capitalist society. New York: HarperBusiness.

Ertmer, P. A., Parisio, M. L., \& Wardak, D. (2013). The practice of educational/instructional design. In R. Luckin, P. Goodyear, B. Grabowski, S. Puntambekar, N. Winters, \& J. Underwood (Eds.), Handbook of design in educational technology (pp. 5-19). New York: Routledge.

Florida, R. (2002). The rise of the creative class and how it's transforming work, life, community and everyday life. New York: Basic Books.

Gosling, D. (2015). Collaborative peer-supported review of teaching. Professional Learning and Development in Schools and Higher Education, 9, 13-31.

Greeno, J. G. (2006). Learning in activity. In R. K. Sawyer (Ed.), Cambridge handbook of the learning sciences (pp. 79-96). New York: Cambridge University Press.

Haslir, M., Lee, T. C., Mohd, S. B., \& Ling, L. Y. (2016). Understanding teacher's principle-based practice in sustaining knowledge building practice in a science classroom. In Proceedings of the 12th International Conference of the Learning Sciences (pp. 1318-1321). Singapore: International Society of the Learning Sciences.

Hatano, G., \& Inagaki, K. (1986). Two courses of expertise. In H. Stevenson, H. Azuma, \& K. Hakuta (Eds.), Child development and education in Japan (pp. 262-272). New York: Freeman.

Hunzicker, J. (2012). Professional development and job-embedded collaboration: How teachers learn to exercise leadership. Professional Development in Education, 38(2), 267-289.

Jewitt, C. (Ed.). (2014). The Routledge handbook of multimodal analysis (2nd ed.). London: Routledge, Taylor \& Francis.

Johnson, R., Severance, S., Leary, H., \& Miller, S. (2014). Mathematical tasks as boundary objects in design-based implementation research. In Proceedings of the 11th International Conference of the Learning Sciences (pp. 1127-1131). Boulder: International Society of the Learning Sciences. 
Kaendler, C., Wiedmann, M., Rummel, N., \& Spada, H. (2015). Teacher competencies for the implementation of collaborative learning in the classroom: A framework and research review. Educational Psychology Review, 27, 505-536.

Kalantzis, M., Cope, B., \& Harvey, A. (2003). Assessing multiliteracies and the new basics. Assessment in Education, 10(1), 15-26.

Kali, Y. (2006). Collaborative knowledge building using the design principles data base. Computer-Supported Collaborative Learning, 1, 187-201.

Kali, Y. (2008). The design principles database as means for promoting design-based research. In A. E. Kelly, R. A. Lesh, \& J. Y. Baek (Eds.), Handbook of design research methods in education (pp. 423-438). New York: Routledge.

Kazmierczak, E. T. (2003). Design as meaning making: From making things to the design of thinking. Design Issues, 19(2), 45-59.

Kim, M. S. (2015). Empowering prospective teachers to become active sense-makers: Multimodal modeling of the seasons. Journal of Science Education and Technology, 24(5), 610-627. https://doi.org/10.1007/s10956-015-9550-z

Kim, M. S. (2019). A systematic review of the design work of STEM teachers. Research in Science and Technological Education. https://doi.org/10.1080/02635143.2019.1682988

Kim, M. S., Hung, W. L., Jamaludin, A. B., \& Lim S. (2012). Expanding 'within context' to 'across contexts' learning: A case study of informal and formal activities, Interactive Learning Environments, 22(6), 704-720.

Krechevsky, M., Mardell, B., Rivard, M., \& Wilson, D. (2013). Visible learners. San Francisco: Jossey-Bass.

Kreijns, K., Kirschner, P. A., \& Jochems, W. (2003). Identifying the pitfalls for social interaction in computer-supported collaborative learning environments: A review of the research. Computers in Human Behavior, 19, 335-353.

Kress, G. (2000). Designs and transformations: New theories of meaning. In B. Cope \& M. Kalantzis (Eds.), Multiliteracies: Literacy learning and the design of social futures (pp. 153-161). South Yarra: Macmillan.

Kress, G. (2003). Literacy in the new media age. London: Routledge.

Laferrière, T., Law, N., \& Montane, M. (2012). An international knowledge building network for sustainable curriculum and pedagogical innovation. International Education Studies, 5(3), 148-160.

Law, N., Yuen, J., \& Tse, H. (2012). A teacher's journey in knowledge building pedagogy. In Proceedings of the 10th international conference of the learning sciences - volume 1 (pp. 212-219). Sydneyt: International Society of the Learning Sciences.

Lee, E. Y. C., Chan, C. K. K., \& van Aalst, J. (2006). Students assessing their own collaborative knowledge building. International Journal of Computer-Supported Collaborative Learning, 1(1), 57-87.

Lee, T. L., Kim, B., Kim, M. S., \& Lee, W. Y. (2012). Finding voices and emerging agency in classroom learning. In Proceedings of the 10th ICLS (pp. 451-458). ISLS.

Lin, X., Schwartz, D. L., \& Hatano, G. (2005). Toward teachers' adaptive metacognition. Educational Psychologist, 40, 245-255.

Little, P. F. B. (2005). Peer coaching as a support to collaborative teaching. Mentoring \& Tutoring: Partnership in Learning, 13(1), 83-94.

Lombardi, M. M. (2007). Authentic learning for the 21st century: An overview. EDUCAUSE Learning Initiative, 1, 1-12.

Lui, M. \& Slotta, J. D. (2013). Exploring evolutionary concepts with immersive simulations. In Proceedings of the 10th ICLS International Conference of the Learning Sciences (pp. 304-311). Madison: International Society of the Learning Sciences

Martinez-Maldonado, R., Goodyear, P., Dimitriadis, Y., Thompson, K., Carvalho, L., Prieto, L. P.., \& Parisio, M. (2015). Learning about collaborative design for learning in a multi-surface design studio. In Proceedings of the 11th International Conference of the Learning Sciences (pp. 174-181). Gothenburg: International Society of the Learning Sciences.

Matuk, C., \& Linn, M. C. (2014). Exploring a digital tool for exchanging ideas during science inquiry. In Proceedings of the 11th ICLS (pp. 895-902). Boulder: ISLS.

McKenney, S. (2018). How can the learning sciences (better) impact policy and practice? Journal of Learning Sciences, 27, 1-7.

McKenney, S., Kali, Y., Markauskaite, L., \& Voogt, J. (2015). Teacher design knowledge for technology enhanced learning: An ecological framework for investigating assets and needs. Instructional Science, 43, 181-202.

Mislevy, R. J., \& Haertel, G. D. (2006). Implications of evidence-centred design for educational testing. Educational Measurement: Issues and Practice, 25(4), 6-20.

Mullins, D., Deiglmayr, A., \& Spada, H. (2013). Motivation and emotion in shaping knowledge co-construction. In Affective learning together: Social and emotional dimensions of collaborative learning (pp. 139-161).

Ontario Ministry of Education. (2015). Pedagogical documentation revisited: Looking at assessment and learning in new ways. Capacity Building Series. http://www.edu.gov.on.ca/eng/literacynumeracy/inspire/research/CBS_PedagogicalDocument.pdf

Papert, S. (1993). The children's machine: Rethinking school in the age of computer. New York: Basic Books.

Pellegrino, J. (2014). A learning sciences perspective on the design and use of assessment in education. In K. Sawyer (Ed.), Cambridge handbook of the learning sciences (2nd ed., pp. 262-282). New York: Cambridge University Press.

Penuel, W. R., \& Gallagher, D. J. (2017). Creating research practice partnerships in education. Boston: Harvard Education Press.

Penuel, W. R., \& Gallagher, L. P. (2009). Preparing teachers to design instruction for deep understanding in middle school earth science. The Journal of the Learning Sciences, 18(4), 461-508.

Pifarré, M., Cobos, R., \& Argelagós, E. (2014). Incidence of group awareness information on students' collaborative learning processes. Journal of Computer Assisted Learning, 30(4), 300-317.

Razzouk, R., \& Shute, V. (2012). What is design thinking and why is it important? Review of Educational Research, 82(3), 330-348.

Reilly, E. (2011). Participatory learning environments and collective meaning making practice. Journal of Media Literacy Education, 3(1), 6-7.

Resendes, M., Scardamalia, M., Bereiter, C., Chen, B., \& Halewood, C. (2015). Group-level formative feedback and metadiscourse. International Journal of Computer-Supported Collaborative Learning, 10(3), 309-336.

Rinaldi, C. (2001). Documentation and assessment: What is the relationship? In C. Giudici, C. Rianldi, \& M. Krechevsky (Eds.), Making learning visible: Children as individual and group leaders (pp. 78-89). Reggio Emilia: Reggio Children.

Rinaldi, C. (2006). In dialogue with Reggio Emilia: Listening, researching and learning. New York: Routledge.

Rogoff, B. (1990). Apprenticeship in thinking: Cognitive development in social context. New York: Oxford University Press.

Rogoff, B. (1998). Cognition as a collaborative process. In D. Kuhn \& R. S. Siegler (Eds.), Handbook of child psychology, 5th edition, vol. 2: cognition, perception, and language (pp. 679-744). New York: Wiley.

Ronfeldt, M., Farmer, S., McQueen, K., \& Grissom, J. (2015). Teacher collaboration in instructional teams and student achievement. American Educational Research Journal, 52(3), 475-514.

Roth, W. M., \& Bowen, G. M. (1995). Knowing and interacting: A study of culture, practices, and resources in a grade 8 openinquiry science classroom guided by a cognitive apprenticeship metaphor. Cognition and Instruction, 13, 73-128. 
Rowsell, J., Kosnik, C., \& Beck, C. (2008). Fostering multiliteracies pedagogy through preservice teacher education. Teaching Education, 19(2), 109-122.

Sadler, R. (1989). Formative assessment and the design of instructional systems. Instructional Science, 18, 119-144.

Sannino, A., Engeström, Y., \& Lemos, M. (2016). Formative interventions for expansive learning and transformative agency. Journal of the Learning Sciences, 25(4), 599-633.

Sawyer, K. (2011). What makes good teachers great? The artful balance of structure and improvisation. In K. Sawyer (Ed.), Structure and improvisation in creative teaching (pp. 1-24). New York: Cambridge University Press.

Sawyer, R. K. (2004). Creative teaching: Collaborative discussion as disciplined improvisation. Educational Researcher, $3(2), 12-20$

Sawyer, R. K. (2007). Group genius: The creative power of collaboration. New York: Basic Books.

Scardamalia, M. (2002). Collective cognitive responsibility for the advancement of knowledge. In B. Smith (Ed.), Liberal education in a knowledge society (pp. 67-98). Chicago: Open Court.

Scardamalia, M., \& Bereiter, C. (2006). Knowledge building: Theory, pedagogy, and technology. In K. Sawyer (Ed.), Cambridge handbook of the learning sciences (pp. 97-118). New York: Cambridge University Press.

Schwartz, D. L., Bransford, J. D., \& Sears, D. (2005). Efficiency and innovation in transfer. In J. Mestre (Ed.), Transfer of learning (pp. 1-51). Greenwich: Information Age Publishing.

Sfard, A. (1998). On two metaphors for learning and the dangers of choosing just one. Educational Researcher, 27(2), 4-13.

Shepard, L. A. (2000). The role of assessment in a learning culture. Educational Researcher, 29(7), 4-14.

Sinha, S., \& Hanuscin, D. L. (2017). Development of teacher leadership identity: A multiple case study. Teaching and Teacher Education, 63, 356-371.

Sparks, D. (2002). Designing powerful staff development for teachers and principals. Oxford: National Staff Development Council.

Stahl, G., Koschmann, T., \& Suthers, D. (2006). Computer-supported collaborative learning: An historical perspective. In R. K. Sawyer (Ed.), Cambridge handbook of the learning sciences (pp. 409-426). Cambridge: Cambridge University Press.

Stoll, L., Bolam, R., McMahon, A., Wallace, M., \& Thomas, S. (2006). Professional learning communities: A review of the literature. Journal of Educational Change, 7(4), 221-258.

Teo, C. L. (2014). Conceptual shifts within problem spaces for knowledge-building practice within a teacher community. In Knowledge creation in education (pp. 205-226). Singapore: Springer.

The Association of Canadian Deans of Education. (2006). Accord on initial teacher education: The context for teacher education in Canada. Retrieved September 29, 2008, from http://www.csse.ca/ACDE/TeacherAccord.pdf

The Design-Based Research Collective. (2003). Design-based research: An emerging paradigm for educational inquiry. Educational Researcher, 32(1), 5-8.

The Institute of Design at Stanford. (2010). An introduction to design thinking process guide. Retrieved on April 22, 2015 from https:/dschool-old.stanford.edu/sandbox/groups/designresources/wiki/36873/attachments/74b3d/ ModeGuideBOOTCAMP2010L.pdf

The New London Group. (1996). A pedagogy of multiliteracies: Designing social futures. Harvard Educational Review, 66(1), 60-92.

The New London Group. (2000). A pedagogy of multiliteracies: Designing social futures. In B. Cope \& M. Kalantzis (Eds.), Multiliteracies (pp. 9-42). London: Routledge.

Valsiner, J., \& Veer, R. V. D. (2000). The social mind. Cambridge: Cambridge University Press.

Van Aalst, J. (2009). Distinguishing knowledge sharing, knowledge construction, and knowledge creation discourses. International Journal of Computer-Supported Collaborative Learning, 4(3), 259-287.

Van Aalst, J., \& Chan, C. K. K. (2007). Student directed assessment of knowledge building using electronic portfolios in knowledge forum. Journal of the Learning Sciences, 16, 175-220.

Van Leeuwen, A. (2015). Learning analytics to support teachers during synchronous CSCL: Balancing between overview and overload. Journal of Learning Analytics, 2(2), 138-162.

Van Leeuwen, A., Janssen, J., Erkens, G., \& Brekelmans, M. (2014). Supporting teachers in guiding collaborative students: Effects of learning analytics in CSCL. Computers \& Education, 79, 28-39.

Van Leeuwen, A., Janssen, J., Erkens, G., \& Brekelmans, M. (2015). Teacher regulation of cognitive activities during student collaboration: Effects of learning analytics. Computers \& Education, 90, 80-94.

Vangrieken, K., Dochy, F., Raes, E., \& Kyndt, E. (2015). Teacher collaboration: A systematic review. Educational Research Review, 15, 17-40.

Wang, F., \& Hannafin, M. J. (2005). Design-based research and technology-enhanced learning environments. Educational Technology Research and Development, 53(4), 5-23.

Wenger, E. (1998). Communities of practice: Learning, meaning, and identity. New York: Cambridge University Press.

Wertsch, J. V. (1993). Voices of the mind: Sociocultural approach to mediated action. Cambridge: Cambridge University Press.

Wiliam, D., \& Thompson, M. (2007). Integrating assessment with instruction: What will it take to make it work? In C. A. Dwyer (Ed.), The future of assessment: Shaping teaching and learning (pp. 53-82). Mahwah: Lawrence Erlbaum Associates.

Wilson, M. (Ed.). (2004). Towards a coherence between classroom assessment and accountability. Chicago: University of Chicago Press.

Yoon, S. A., Anderson, E., Koehler-Yom, J., Klopfer, E., Sheldon, J., Wendel, D., Schoenfeld, I., Scheintaub, H., Oztok, M., \& Evans, C. (2015). Design features for computer-supported complex systems learning and teaching in high school science classrooms. In Proceedings of the 11th International Conference of the Learning Sciences (pp. 102-109). Gothenburg: International Society of the Learning Sciences.

York-Barr, J., \& Duke, K. (2004). What do we know about teacher leadership? Findings from two decades of scholarship. Review of Educational Research, 74(3), 255-316.

Zhang, J., Hong, H. Y., Scardamalia, M., Teo, C. L., \& Morley, E. A. (2011). Sustaining knowledge building as a principle-based innovation at an elementary school. The Journal of the Learning Sciences, 20(2), 262-307.

Zhang, J., Scardamalia, M., Reeve, R., \& Messina, R. (2009). Designs for collective cognitive responsibility in knowledge-building communities. Journal of the Learning Sciences, 18(1), 7-44.

\section{Publisher's Note}

Springer Nature remains neutral with regard to jurisdictional claims in published maps and institutional affiliations. 